\title{
Therapeutic cancer vaccines and combination immunotherapies involving vaccination
}

\author{
This article was published in the following Dove Press journal: \\ ImmunoTargets and Therapy \\ 6 October 2014 \\ Number of times this article has been viewed
}

\author{
Trang Nguyen' \\ Julie Urban' \\ Pawel Kalinski ${ }^{1-5}$ \\ 'Department of Surgery, ${ }^{2}$ Department \\ of Immunology, ${ }^{3}$ Department of \\ Microbiology and Infectious Disease, \\ ${ }^{4}$ Department of Bioengineering, \\ University of Pittsburgh, ${ }^{5}$ University \\ of Pittsburgh Cancer Institute, \\ Pittsburgh, PA, USA
}

\begin{abstract}
Recent US Food and Drug Administration approvals of Provenge ${ }^{\circledR}$ (sipuleucel-T) as the first cell-based cancer therapeutic factor and ipilimumab (Yervoy ${ }^{\circledR} /$ anticytotoxic T-lymphocyte antigen-4) as the first "checkpoint blocker" highlight recent advances in cancer immunotherapy. Positive results of the clinical trials evaluating additional checkpoint blocking agents (blockade of programmed death [PD]-1, and its ligands, PD-1 ligand 1 and 2) and of several types of cancer vaccines suggest that cancer immunotherapy may soon enter the center stage of comprehensive cancer care, supplementing surgery, radiation, and chemotherapy. This review discusses the current status of the clinical evaluation of different classes of therapeutic cancer vaccines and possible avenues for future development, focusing on enhancing the magnitude and quality of cancer-specific immunity by either the functional reprogramming of patients' endogenous dendritic cells or the use of ex vivo-manipulated dendritic cells as autologous cellular transplants. This review further discusses the available strategies aimed at promoting the entry of vaccination-induced T-cells into tumor tissues and prolonging their local antitumor activity. Finally, the recent improvements to the above three modalities for cancer immunotherapy (inducing tumor-specific T-cells, prolonging their persistence and functionality, and enhancing tumor homing of effector T-cells) and rationale for their combined application in order to achieve clinically effective anticancer responses are addressed.
\end{abstract}

Keywords: immunotherapy, cancer, vaccines

\section{Introduction}

Current comprehensive cancer care is centered on reducing the bulk of disease through surgery, chemotherapy, and radiation. Despite the increasing effectiveness of these cornerstones of treatment and high cure rates of multiple cancer forms, cancer remains a leading cause of death. ${ }^{1}$ Recent breakthroughs in cancer immunotherapy have added several promising new therapies to the traditional armamentarium of oncology treatment regimens.

The strategy of utilizing the immune system in the treatment of cancer dates back to the 1890 s and the work of William Coley. ${ }^{2}$ Coley observed that some tumors regress in the setting of acute bacterial infection. He attempted to recapitulate this phenomenon by studying the injection of heat-inactivated Streptococcus erysipelas and Serratia marcescens (Coley's toxins) in cancer patients. The field of cancer immunology and immunotherapy has greatly advanced since Coley's initial studies, a time when little was known about the mechanisms underlying the antitumor effects of bacterial toxins. There is now a growing understanding of how the immune system identifies tumor cells and targets them for elimination. Just as important is the growing understanding
Correspondence: Pawel Kalinski University of Pittsburgh and the University of Pittsburgh Cancer Institute, Hillman Cancer Center, UPCI Research Pavilion, Suite I.46, 5117 Center Ave, Pittsburgh,

PA 15213-1863, USA

Tel +I 4I2623 77I2

Fax +I 4126237709

Email kalinskip@upmc.edu 
of how tumors can undermine the immune system's ability to recognize and eliminate cancer cells.

Briefly, an adaptive immune response against tumor cells is classically believed to be initiated when tissue-resident antigen-presenting cells, such as dendritic cells, take up and process tumor-specific or tumor-associated antigens, and present these antigens in the context of major histocompatibility complex (MHC) complexes to naïve T-cells in secondary lymphoid organs. Naïve T-cells can differentiate and expand into different classes of antigen-specific T-cells, including cluster of differentiation (CD) $4^{+} \mathrm{T}$ helper cells and CD8 ${ }^{+}$effector cytotoxic T lymphocytes (CTLs). At each step of this process, various signals shape whether an antitumor T-cell response will be produced, or conversely, an immunosuppressive and/or tolerogenic response will be made by such mediators as regulatory T-cells and myeloid-derived suppressor cells (reviewed by Palucka and Banchereau, ${ }^{3}$ Chen and Mellman, ${ }^{4}$ and Blattman and Greenberg ${ }^{5}$ ). Immunotherapies for cancer can target each or many of these steps to skew toward an antitumor response and away from an immunosuppressive response.

Cancer immunotherapies can be categorized as nonantigen-specific or antigen-specific therapies. Non-antigenspecific immunotherapies aim to either enhance the immune response in a general fashion or to decrease the immunosuppression present in the tumor environment. Non-antigen-specific therapies include cytokines and immune growth factors (eg, interferon (IFN]- $\alpha$, interleukin [IL]-2, or granulocyte macrophage colony-stimulating factor), immunologic adjuvants (eg, Bacille Calmette-Guérin); Toll-like receptor (TLR)-3 agonists, such as poly-I:C (Rintatolimod, Ampligen $^{\circledR}$; Hemispherx Biopharma, Inc., Philadelphia, PA, USA) and poly-ICLC (Hiltonol ${ }^{\circledR}$; Oncovir, Washington, DC, USA); TLR-4 agonists, such as monophosphoryl lipid A; the TLR-7 agonist, imiquimod; immune checkpoint blockers, eg, anticytotoxic T-lymphocyte antigen-4 (CTLA-4) antibody; ${ }^{6,7}$ and the programmed death-1 (PD-1) pathway agents, nivolumab and lambrolizumab. ${ }^{8-11}$

Compared with non-specific immunotherapies, antigenspecific therapies, such as therapeutic vaccines against cancer, aim to induce immune cells to target cancer cells that express a particular set of antigens. Different classes of cancer vaccines include peptide-based or protein-based vaccines, cancer cell-based vaccines, viral vector vaccines, DNA vaccines, messenger RNA vaccines, and carbohydrate vaccines. ${ }^{12-19}$ In all cases, these vaccines involve two components, an antigen and an adjuvant, aimed at promoting local inflammation and the resulting immunization. Additionally, all of the above types of cancer vaccines rely on the patients' endogenous dendritic cells (DCs) for their uptake and effective antigen presentation to tumor-specific $\mathrm{CD}^{+}$and $\mathrm{CD}^{+}$ T-cells.

Another category of cell-based cancer vaccines is use of patients' ex vivo-generated and tumor antigen-loaded DCs (or more precisely, autologous cellular therapeutics). This strategy limits the dependence of the immune system on patients' resident DCs, which have been shown to be defective in the advanced stages of cancer $^{3,20,21}$ or even redirected to differentiate toward myeloid-derived suppressor cells. ${ }^{22,23}$ Regardless of whether endogenous or ex vivo-generated DCs are utilized for immunization, therapeutic cancer vaccines need to overcome several common challenges to induce immunity in the presence of established tumors and can benefit from recent developments in the area of DC biology.

\section{Challenges in therapeutic cancer vaccination}

For a therapeutic cancer vaccine to be effective, it must be capable of inducing a high number of antigen-specific T-cells against an established tumor, which can migrate to the tumor and perform their effector functions at the tumor site (Figure 1). However, challenges are present for each of these three goals. The first challenge is achieving high numbers of antitumor T-cells when the vaccine is being administered in the presence of an ongoing, although dysfunctional, immune response. Due to the ongoing antitumor immune response, the vaccine-carrying antigen-presenting cells (using either endogenous DCs that have taken up vaccine-introduced antigens or ex vivo-generated tumor antigen-loaded DCs), may be recognized by the $\mathrm{CD} 8^{+} \mathrm{T}$-cells as "tumor". ${ }^{24,25}$ Since this encounter occurs in the periphery, away from the immunosuppressive tumor microenvironment, the $\mathrm{CD} 8^{+}$ T-cells may be capable of eliminating the vaccine, and thus limiting the vaccine's effectiveness before it can induce an immune response. ${ }^{3}$

Additionally, there is a lack of the proinflammatory signals required to promote effective immune responses. These signals are replaced by tumor-induced immunosuppressive/anti-inflammatory signals predominating in cancer patients. Therefore, to achieve the goal of inducing high numbers of tumor-specific T-cells, the vaccine-carrying antigen-presenting cells must not only survive long enough to present antigen, but must also provide the inflammatory signals to drive effector cell functions. ${ }^{3,26-28}$

Unfortunately, the presence of high numbers of antigenspecific T-cells does not ensure an effective antitumor 


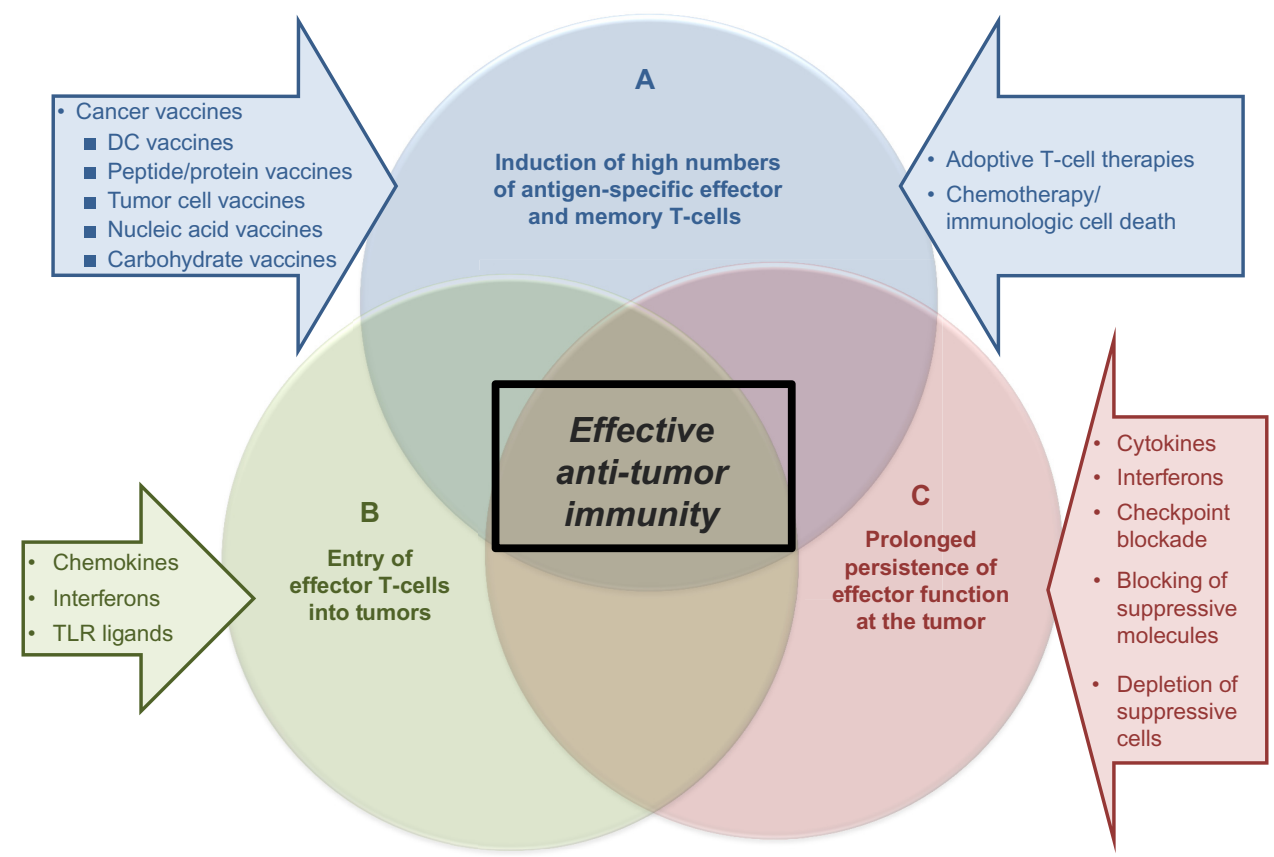

Figure I Elements of effective antitumor immunity.

Notes: Effective antitumor responses involve numerous features of immunity. These include $(\mathbf{A})$ induction of high numbers of type I (cytotoxic/IFN- $\gamma$-producing) antigenspecific T-cells against an established tumor. This can be accomplished with various types of cancer vaccines. Other therapies that are not the focus of this review are adoptive T-cell therapies and certain chemotherapeutic agents that promote immunologic cell death. ${ }^{137,138}$ Furthermore, the ability of vaccination-induced tumor-specific T-cells depends on the T-cells' ability to enter tumor tissues (B), which can be facilitated by manipulations aimed at local induction of effector cell (cytotoxic T lymphocyte, type I helper $\mathrm{CD}^{+} \mathrm{T}$ cell, natural killer)-attracting chemokines, especially when accompanied by suppression of factors that attract undesirable suppressive cells, such as myeloid-derived suppressor cells and regulatory T-cells. Finally, sustaining effector functions at the tumor site (C) can be supported by promoting effector T-cell activity and prolonging T-cell memory, which can be achieved with administration of cytokines such as IL-I, IL-7, IL-I2, and IL-I5 or IFNs, and by counteracting immunosuppressive mechanisms using checkpoint blockade of cytotoxic T-lymphocyte antigen-4 or the PDI-PDLI/2 pathway, blockers of immunosuppressive molecules like prostaglandin E2, indoleamine 2,3-dioxygenase, nitric oxide synthase, vascular endothelial growth factor, and transforming growth factor beta, or depletion of immunosuppressive cells such as regulatory T-cells and myeloid-derived suppressor cells.

Abbreviations: CD, cluster of differentiation; DC, dendritic cell; IFN, interferon; IL, interleukin; PD, programmed death-I; PDL, programmed death ligand; TLR, toll-like receptor.

response if these T-cells are unable to home to the tumor. In a normal infection scenario, where the immune response is targeting invading pathogens, the microorganisms and local tissue damage induce chemokines that recruit effector cells such as CTLs, type 1 helper $\mathrm{CD}^{+} \mathrm{T}$-cells, or natural killer cells to the site of pathogen entry. ${ }^{27,29}$ However, one of the immune evasion mechanisms evoked by tumors to support tumor growth and metastatic spread is downregulation of the chemokines that attract immune effector cells ${ }^{28,29}$ and upregulation of chemokines that attract suppressor cells, such as regulatory T-cells, ${ }^{30-32}$ suppressive plasmacytoid DCs, ${ }^{33}$ and myeloid-derived suppressor cells. ${ }^{34,35}$ Thus, a therapeutic vaccine needs to either induce T-cells that can respond to the spontaneously expressed tumor-associated chemokines or be administered as part of a combinatorial therapy with additional factors to alter the chemokine profile in the tumor microenvironment. ${ }^{32,34}$

Once high numbers of vaccine-induced tumor-specific T-cells have been generated and arrive at the tumor site, the T-cells must be capable of killing the tumor cells in order for the vaccine to be effective. Most types of cancer (including melanoma, ovarian, breast, renal, prostate, lung, and head and neck cancer) produce many factors, including IL-10, transforming growth factor beta, vascular endothelial growth factor, IL-6, and cyclooxygenase-2 products like prostaglandin E2, that contribute to immune dysfunction by suppressing the functions of endogenous or adoptively transferred DCs and T-cells. ${ }^{21,36-38}$ These factors not only act to directly suppress DC and T-cell functions, but they can also promote cell-mediated immune suppression by enhancing the recruitment, expansion, and activation of regulatory T-cells and myeloid-derived suppressor cells..$^{30,31,39,40}$ While in some patients the high numbers of tumor-specific T-cells induced by the vaccine may be able to overcome the immunosuppressive tumor microenvironment, most therapeutic cancer vaccine strategies would greatly benefit from a combinatorial approach that alters the tumor to reduce immunosuppressive factors. 


\section{Promise and challenges in therapeutic cancer vaccines: clinical trials}

The development of clinically effective therapeutic cancer vaccines has been challenging. Currently, the only therapeutic cancer vaccine approved by the US Food and Drug Administration is sipuleucel-T, a treatment for metastatic androgen-independent prostate cancer that was approved in 2010. ${ }^{41,42}$

Sipuleucel-T consists of antigen-presenting cells that are activated ex vivo from autologous peripheral blood mononuclear cells by a fusion protein, PA2024, which is comprised of granulocyte macrophage colony-stimulating factor and prostatic acid phosphatase, a prostate adenocarcinomaassociated antigen. ${ }^{41,43}$ In two randomized, double-blind, placebo-controlled multicenter Phase III trials, sipuleucel-T increased median survival by 4 months when compared with placebo. ${ }^{43,44}$ Sipuleucel-T was administered in three doses at weeks 0,2 , and 4 , each at 2 days following leukapheresis. In the D9901/D9902A trials of 225 patients with asymptomatic metastatic hormone-refractory prostate cancer randomized in a 2:1 ratio to treatment with sipuleucel-T or a control infusion, the primary objective was time to disease progression. While there was no statistically significant difference in time to progression (median 11.1 weeks with sipuleucel-T versus 9.7 weeks with control), there was a $33 \%$ reduction in risk of death with sipuleucel-T compared with control and a statistically significant difference in survival (median 23.2 months for sipuleucel-T versus 18.9 months for control, $P=0.011){ }^{44}$ In the IMPACT (Immunotherapy for Prostate Adenocarcinoma Treatment) study of 127 metastatic castration-resistant prostate cancer patients with the primary endpoint of overall survival, there was a $22 \%$ adjusted relative reduction in risk of death and a statistically significant increase in median survival of 4.1 months (median 25.8 months for sipuleucel-T versus 21.7 months for placebo, $P=0.03$ ), although there was no difference in disease progression. ${ }^{43}$ Patients in the treatment group who had antibody titers of more than 400 against PA2024 had an increased survival compared with those who had titers of less than $400(P<0.001) .{ }^{43}$ Cumulative antigenpresenting cell activation measured by CD54 upregulation, antigen-presenting cell number, total nucleated cell number, and antigen-specific immune responses to PA2024 and/or prostatic acid phosphatase in the treatment group correlated with overall survival $(P<0.05) .{ }^{41}$

The ClinicalTrials.gov registry gives an insight into upcoming cancer vaccines in development that show promise in improving outcomes. ${ }^{45} \mathrm{~A}$ query of this website in November 2013 with a targeted search of Phase III and IV clinical trials with known statuses and "cancer" listed as the condition, "vaccine" as the intervention, and "survival" as the outcome measure, resulted in 42 studies. A summary of selected cancer-specific vaccines from this query is listed in Table 1 with additional information from publications and abstracts. ${ }^{43,46-55}$

In addition to the sipuleucel-T trials, a Phase III trial of a glycoprotein 100 peptide vaccine also posted positive results. In a randomized, multicenter trial, patients with advanced melanoma received IL-2 and glycoprotein 100:209-217 (210 M) peptide vaccination or IL-2 alone. ${ }^{47}$ For the primary endpoint of clinical response, the IL-2 with vaccination group had a significantly higher response rate of $20 \%$ (complete response $11 \%$, partial response $9 \%$ ) versus a response rate of $10 \%$ in the IL-2 only group (complete response $2 \%$, partial response $8 \% ; P=0.05$ ). Median progression-free survival was also significantly longer in the IL-2 with vaccination group (2.2 months) than in the IL-2 alone group (1.6 months; $P=0.008)$. There was a trend of increased overall survival with the addition of vaccination to IL-2 (17.8 months) compared with IL-2 alone (11.1 months; $P=0.06$ ). It is important to note that this study was not powered to detect a difference in overall survival.

Several Phase III trials of therapeutic cancer vaccines are currently in progress. Another vaccine in Phase III trials is TG4010, a poxvirus vector vaccine encoding for the tumor-associated antigen Mucin-1 (MUC1) and IL-2, which is being investigated in non-small cell lung cancer (NSCLC). ${ }^{49}$ IMA901, a multiple peptide vaccine for renal cell carcinoma, has also completed accrual for its Phase III study and its results are pending. The ten peptides for IMA901 were uniquely chosen using an antigen discovery platform that analyzed renal cell carcinoma tissue..$^{56}$ The HyperAcute ${ }^{\circledR}$ vaccines (NewLink Genetics, Ames, IA, USA) for pancreatic and NSCLC consist of allogeneic cancer cells that have been genetically modified to express murine $\alpha(1,3)$ galactosyl. ${ }^{50,51}$

ProstAtak $^{\mathrm{TM}}$ (Advantagene Inc., Auburndale, MA, USA) and Prostvac ${ }^{\circledR}$-V/F-TRICOM ${ }^{\mathrm{TM}}$ (Bavarian Nordic; Washington, DC, USA) are viral-based vaccines for prostate cancer. ProstAtak involves intratumoral injection of an adenovirus containing a Herpes virus thymidine kinase gene followed by valaciclovir. Prostvac-V/F-TRICOM is composed of recombinant vaccinia and fowlpox viral vectors that encode for prostate-specific antigen and TRICOM, a combination of three costimulatory molecules, LFA-3, B7.1, and intercellular adhesion molecule- 1.52 


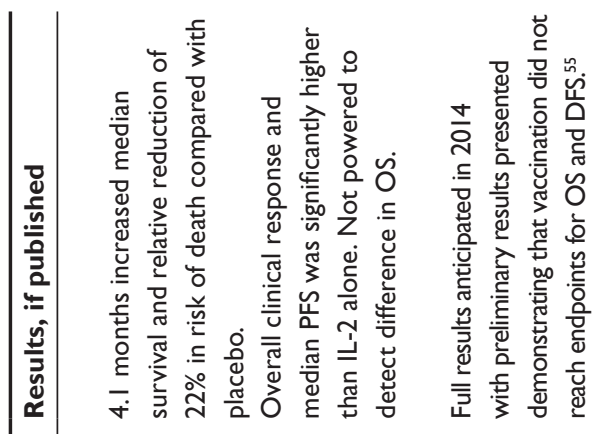

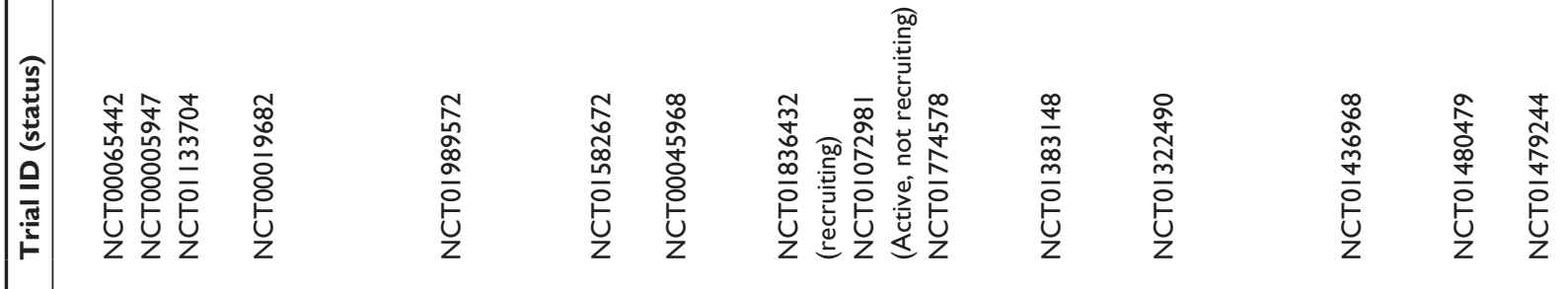

III I In

Wh

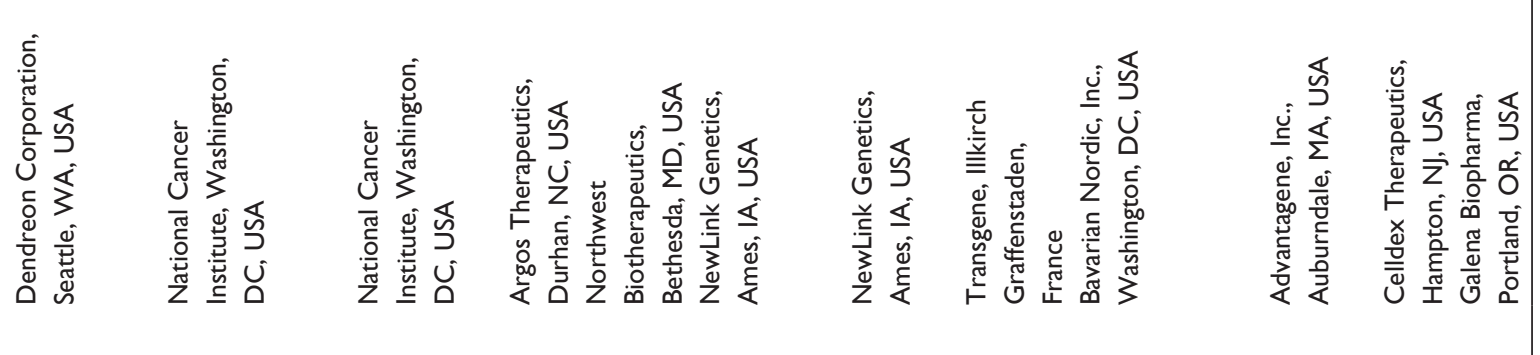

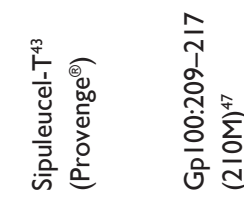

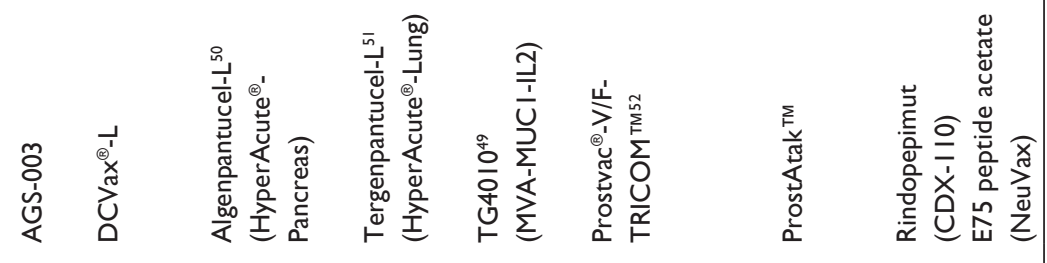

0
0

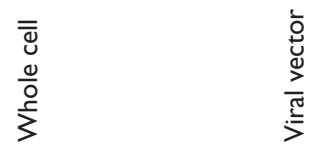

$\frac{\stackrel{0}{\frac{\pi}{0}}}{\frac{0}{0}}$ 


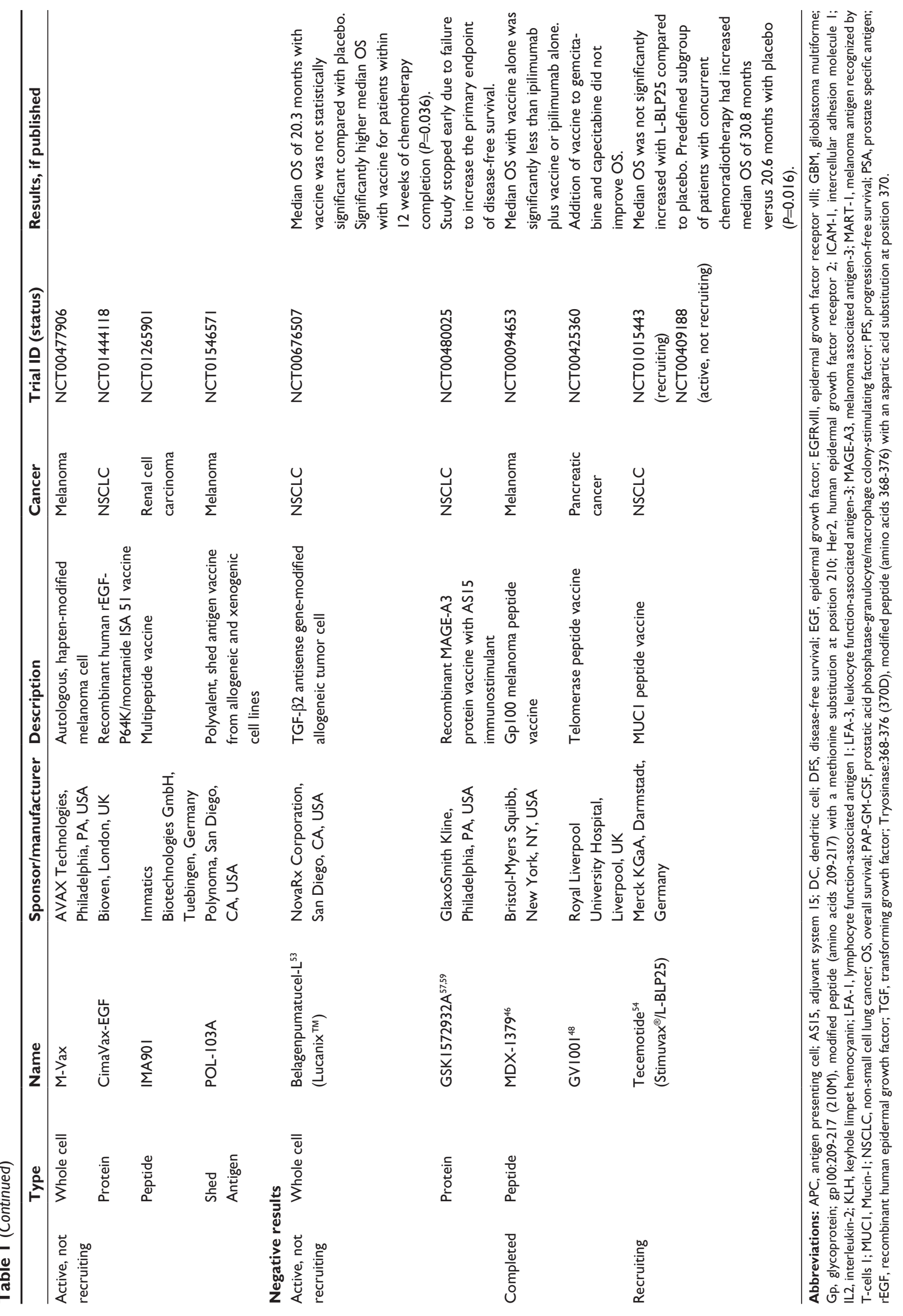


A few Phase III trials have failed to meet their primary endpoints, and highlight the difficulties of cancer vaccine development. One of the largest studies in NSCLC, the MAGRIT (MAGE-A3 as Adjuvant NSCLC Immunotherapy) trial, which utilized a melanoma-associated antigen 3 (MAGE-A3) protein vaccine, was stopped in early 2014 after failing to increase the primary endpoint of disease-free survival in MAGE-A3-positive patients overall or MAGE-A3positive patients without chemotherapy treatment, compared with control. ${ }^{57-59}$ This was following a double-blind, randomized, placebo-controlled Phase II study that showed clinical activity, with all treated patients developing anti-MAGE-A3 antibodies and with a pretreatment 84-gene expression signature being associated with increased disease-free response. ${ }^{60,61}$ However, the subsequent Phase III trial was not able to determine a subpopulation of gene signature-positive patients who would benefit from treatment since there was an insufficient treatment effect. ${ }^{59}$

Belagenpumatucel-L, an allogeneic genetically modified NSCLC tumor cell vaccine, showed a trend toward increased median survival but this did not reach statistical significance. ${ }^{53}$ However, the subgroup of patients who received vaccination within 12 weeks of chemotherapy had a statistically significant improvement, and the study is continuing in this subgroup of patients. Similarly, tecemotide, a MUC1 peptide vaccine for NSCLC, failed to demonstrate a statistically significant difference in overall survival compared with placebo, but a significant increase in median overall survival in the subgroup of patients who had concurrent chemoradiation has led to plans for a randomized trial of tecemotide with concurrent chemoradiation in stage III NSCLC patients. ${ }^{54}$

One of the largest studies in metastatic melanoma was MMAIT-IV (Malignant Melanoma Active Immunotherapy Trial for Stage IV Disease), an international, multicenter, randomized, double-blind Phase III trial in 1,656 stage III and IV patients of an allogeneic whole melanoma cell vaccine, Canvaxin ${ }^{\mathrm{TM}}$ (CancerVax Corporation, Carlsbad, CA, USA) with a Bacille Calmette-Guérin adjuvant, compared with placebo plus Bacille Calmette-Guérin, that was closed early after interim analysis showed a low probability of demonstrating a significant increase in survival in the Canvaxin with Bacille Calmette-Guérin arm. ${ }^{62}$ Although the trial had negative results, an ancillary study of pretreatment and posttreatment circulating tumor cell biomarkers for melanoma antigen recognized by T-cells 1 (MART1), MAGE-A3, and paired box 3 (PAX3) from patients in the MMAIT-IV trial was able to demonstrate that pretreatment and serial circulating tumor cell levels were significantly associated with decreased disease-free survival and overall survival. ${ }^{63}$

Another large melanoma vaccine study, the randomized Phase III trial of adjuvant ganglioside (GM2) conjugated to Keyhole Limpet hemocyanin (KLH) admixed with adjuvant QS-21 (GM2-KLH/QS-21) vaccine versus observation in 1,314 stage II melanoma patients, was terminated after the second interim analysis due to failure to increase recurrencefree survival and a trend toward increased overall survival in the observation arm, which was also confirmed on final analysis after a median follow-up of 4 years. ${ }^{64}$

A challenge in evaluating therapeutic cancer vaccines is appropriate patient selection. While clinical trials of new oncologic therapies are traditionally first tested in patients with advanced cancers who have failed multiple treatment regimens, vaccines may be more effective when the disease burden is low. ${ }^{65}$ Another challenge in trial design and evaluation is that the kinetics of tumor growth rates for vaccine therapy differ from those of traditional chemotherapy and radiotherapy. ${ }^{66}$ Compared with these directly cytotoxic therapies in which the treatment response occurs immediately following their administration and the tumor growth rate often returns to pretreatment levels following termination of treatment, positive responses to vaccine therapy may begin months after treatment, with a potentially prolonged treatment effect persisting long after administration. ${ }^{67}$ Therefore, the intermediate endpoint of progression-free survival based on the commonly used Response Evaluation Criteria in Solid Tumors or World Health Organization criteria has very limited value in vaccine therapies, and more relevant immunologic endpoints are needed. ${ }^{66-68} \mathrm{~A}$ common phenomenon with immunotherapy trials is that overall survival may improve without a change in progression-free survival. ${ }^{43,46,69}$ In fact, there may even be a treatment response after initial progression or tumor growth. ${ }^{67}$ In result, the recently formulated immune-related response criteria ${ }^{67}$ are better predictors of prolonged overall survival of patients treated with immunotherapy than the classical response criteria used to evaluate the effectiveness of chemotherapeutic agents (Response Evaluation Criteria In Solid Tumors [RECIST] and World Health Organization). ${ }^{67}$

Finally, another important trial design consideration is immunologic selection and response monitoring of patients. Pretreatment markers would help to determine which patients would benefit the most from vaccine treatment but this work is still in its infancy. ${ }^{70}$ The discovery of markers to monitor immune responses that correlate with clinical outcomes is still in development. Current biomarkers to evaluate the immune response focus on CTL antigen recognition and 
the humoral response. Markers shown to correlate with clinical outcome include antigen-specific T-cell response based on IFN- $\gamma$ enzyme-linked ImmunoSpot (ELISPOT) assays, cytokine expression levels, and reduction in regulatory T-cells. ${ }^{41,71-73}$

Furthermore, two clinical trials involving DC vaccines indicated a role of DC-produced IL-12p70 as a predictive marker of the clinical benefit of vaccination. ${ }^{74,75}$

\section{Avenues for improved immunization: exploiting the biology of dendritic cells}

The primary aim of cancer vaccines is to generate a CTL response against cancer cells. ${ }^{76}$ An important advantage of therapeutic immunizations, compared with traditional cancer treatments, is that the treatment effect is typically durable due to the induction of long-lived effector memory and central memory T-cells, which can persist for prolonged periods after administration of the vaccine. The second advantage is the very high selectivity of the immune response in targeting tumor cells, while not damaging healthy tissue. As mentioned before, several strategies, such as protein or DNA vaccines, utilize a patient's endogenous DCs at the injection site for uptake and presentation of tumor antigens, but the observed dysfunction of DCs in cancer patients due to tumor-related suppressive factors may limit the effectiveness of these vaccines, which rely on endogenous DCs for antigen uptake. ${ }^{37,77-79}$ Therefore, the use of ex vivo-generated DC vaccines is an attractive option for circumventing this issue, enabling DCs to mature in the absence of tumor-related immunosuppression and allowing more control of the DC maturation process to direct the nature of the immune response.

Effective induction of an antigen-specific T-cell response requires delivery of at least four types of signals (Figure 2) by DCs, each of which can be optimized to improve the cancer vaccine. ${ }^{80}$ The first signal (signal 1) is the presentation of processed antigen in the context of MHC molecules by DCs to naïve T-cells via the T-cell receptor. ${ }^{81}$ One of the key characteristics of DCs that makes these cells a unique tool for cancer vaccination is their ability to take up different forms of antigens, process them, and then cross-present these antigens to naïve $\mathrm{CD} 4^{+}$and $\mathrm{CD} 8^{+}$

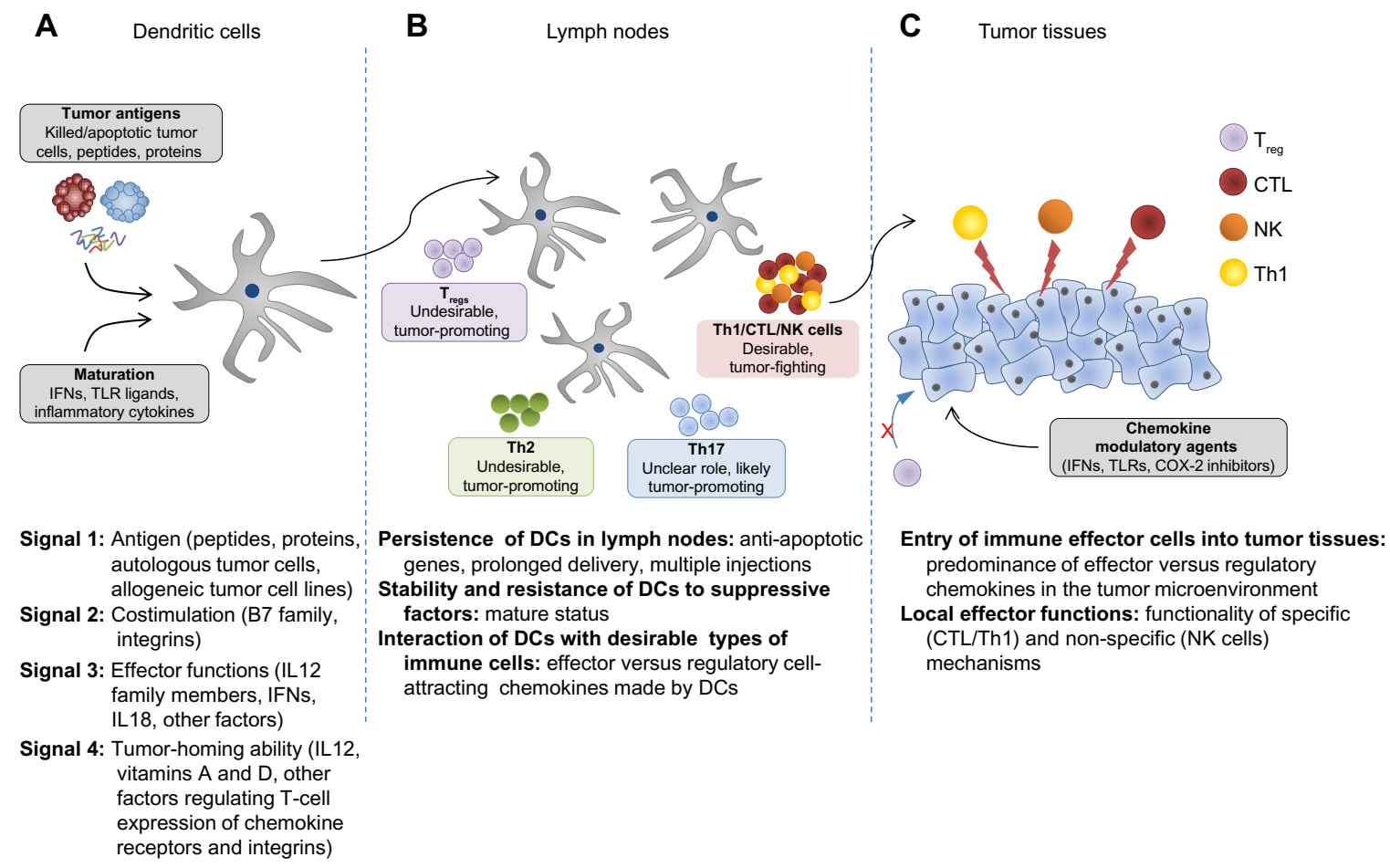

Figure 2 Four types of DC-mediated signals regulating the magnitude and quality of tumor-specific T-cell responses.

Notes: (A) An effective cancer vaccine needs to promote delivery of four types of signals to T-cells. DC-delivered antigenic (signal I) and costimulatory (signal 2) signals are required for T-cell activation and expansion. Signal 3 (polarization of effector mechanisms of immune responses) drives the type of differentiation of T-cells (ie, type I cellmediated response or type 2 humoral response). Signal 4 imprints the tumor-homing ability of T-cells by regulating the profile of chemokine receptor expression on activated T-cells. (B) Additional requirements of vaccine stimulated DCs include the ability to migrate to and persist in draining lymph nodes and preferentially interact with desirable types of immune cells (CTL, ThI, and NK cells, rather than MDSCs and regulatory T-cells). (C) Activated effector cells need to migrate to the tumor tissue and overcome the immunosuppressive mechanisms of the tumor environment in order to have sustained antitumor activity.

Abbreviations: COX2, cyclooxygenase-2; CTL, cytotoxic T lymphocyte; DC, dendritic cell; IFN, interferon; IL, interleukin; MDSCs, myeloid derived suppressor cells; TLR, toll-like receptor; ThI, type I helper; Th2, type 2 helper; Th 17, type 17 helper; $\mathrm{T}_{\text {regs }}$, regulatory T-cells. 
T-cells. This broadens the source of antigens that can be used in vaccines to include not only peptides (which are MHC-restricted and limited to known, well characterized tumor antigens and thus only applicable to patients who express the appropriate MHC haplotype and have tumors that express the specific antigen), but also recombinant proteins, tumor lysates, or whole tumor cells from either autologous or allogeneic sources. The use of proteins or whole cell sources of antigen increases the ability to prime immune responses to undefined patient-specific tumor antigens. Various methods of processing tumor cells for loading have been studied, such as freeze-thaw lysates, irradiation, and oxidation of tumor cells, to enhance the uptake and cross-presentation of whole tumor cells by DCs. ${ }^{79,82-84}$ Of note, loading DCs with apoptotic cells was shown to be more effective in stimulating CTLs compared with loading with necrotic cells. ${ }^{85}$

Signal 2 involves costimulatory signals that amplify the T-cell receptor signal and prolong the MHC:T-cell receptor interaction to ensure T-cell activation. This amplification signal is provided by B7 family molecules, such as CD80 and CD86, that bind to CD28 on the T-cell. ${ }^{86,87}$ The MHC:T-cell receptor and CD28:CD80/CD86 interactions are stabilized by integrins, notably leukocyte function-associated antigen-1 (LFA-1): intercellular adhesion molecule-1 interactions, so that the cell-cell interactions are not prematurely terminated, resulting in incomplete activation. ${ }^{88}$ The absence of costimulation during antigen presentation by DCs can induce $\mathrm{CD} 8^{+} \mathrm{T}$-cell tolerance to the antigen. ${ }^{89}$ The molecules involved in costimulation are upregulated upon DC maturation, when the DC also gains the ability to respond to the lymph node-homing chemokines CCL (chemokine [CC motif ligand]-19 and CCL22) by upregulating CC chemokine receptor type 7 (CCR7). ${ }^{90,91}$ The first generation of DC vaccines utilized immature or partially matured DCs capable of cross-presentation of antigens but deficient in costimulatory and lymph node-homing abilities. ${ }^{86}$ This led to protocols for DC maturation producing the "second generation" of DC vaccines that are able to provide both signals 1 and 2 . In these protocols, the DCs are matured using either monocyte-conditioned medium ${ }^{92}$ or a cytokine cocktail consisting of IL-6, IL1 $\beta$, tumor necrosis factor alpha, and prostaglandin E2. ${ }^{93}$ While these maturation strategies induce upregulation of costimulatory molecules and CCR7, and have enhanced immunogenicity in vitro and in vivo in healthy volunteers, their initial promise diminished in a randomized multicenter Phase III trial for advanced melanoma when less than $5 \%$ of patients receiving the vaccine demonstrated a clinical response and there was no impact on overall survival. ${ }^{94}$

Signal 3 is the DC-produced cytokine profile that skews the type of immune response generated (ie, type 1 cell-mediated versus type 2 humoral responses), and provides survival and differentiation signals to naïve T-cells. A prototypical example of a signal 3 cytokine that promotes cell-mediated immunity is IL-12p $70,{ }^{95}$ which is produced by DCs when they are matured in the presence of IFN- $\gamma$, a cytokine produced by activated natural killer cells at the site of infection, and in the absence of the chronic inflammatory cytokine, prostaglandin E2. One possible factor in the negative results of the clinical trials using "second generation" DCs is the use of prostaglandin E2-containing maturation cocktails, since prostaglandin E2 has subsequently been shown to have a deleterious effect on IL-12p70..$^{95-97}$

In order to generate mature DCs with high costimulatory molecules and lymph node-homing ability, as well as high IL-12-producing capacity to promote the desirable cell-mediated immunity, a "third generation" of DCs was generated. ${ }^{73,74}$ The "third generation" DCs are generally matured in conditions mimicking viral infection, which predominantly drives cell-mediated immunity. Some of the strategies to mature DCs are: to coculture immature DCs with other immune cells, such as IL-18 activated natural killer cells ${ }^{98}$ or memory $\mathrm{CD}^{+} \mathrm{T}$-cells; ${ }^{25,99}$ to mature with conditioned medium from activated CTLs, ${ }^{100,101}$ or to use cytokine cocktails that include viral-mimicking TLR ligands. ${ }^{102-107}$ Each of these strategies generate DCs that are "type 1 polarized" (DC1), possessing not only high antigen cross-presentation and costimulatory abilities, but also a superior ability to secrete IL12 for up to 48 hours after interaction with CD40L-expressing CD4 ${ }^{+}$ T-cells. ${ }^{102,103,108-110}$ Additional inclusion of IFN- $\alpha$ to a "type 1 polarizing" cytokine cocktail consisting of IFN- $\gamma$, IL1 $\beta$, tumor necrosis factor alpha, and poly-I:C enhanced the expression of the lymph node homing chemokine receptor CCR7. ${ }^{11-113}$ These $\alpha \mathrm{DC} 1 \mathrm{~s}$ also preferentially produce chemokines that promote migration of naïve, memory, and effector T-cells, but show reduced expression of chemokines that promote immunosuppressive cell recruitment, further enhancing the ability of $\alpha \mathrm{DC} 1 \mathrm{~s}$ to interact and prime strong antitumor immune responses. ${ }^{111-113}$ A recent clinical trial utilizing $\alpha \mathrm{DC} 1$ vaccines and an alternative type of "type 1 polarized DCs" induced by the combination of CD40L and IFN- $\gamma$ demonstrated that the ability of DC1 vaccines to produce high IL-12p70 levels was the strongest predictor of prolonged progression-free survival in vaccinated patients. $^{74,75}$ 
The last type of signal (signal 4) delivered to T-cells during priming interactions with DCs results in programming of specific chemokine receptor expression on activated T-cells that directs them to specific tissues. ${ }^{86}$ In vitro and ex vivo studies have demonstrated that different DC subsets isolated from various tissues can modulate the chemokine expression profile on activated T-cells, thereby directing T-cells back to the tissues of DC origin. ${ }^{14,115}$ This differential chemokine expression programming is not limited to DCs developed in various tissues in vivo, but also extends to ex vivo-generated, cytokine-matured DCs. A comparison of $\mathrm{CD}^{+} \mathrm{T}$-cells from melanoma patients sensitized ex vivo by either prostaglandin E2-matured DCs (second generation) or type 1 polarized DC1s (third generation) demonstrated different chemokine expression on the activated CD8 ${ }^{+}$T-cells. ${ }^{97}$ Specifically, T-cells sensitized by DC1s had higher expression of CCR5 and CXC chemokine receptor 3 (CXCR3), two chemokine receptors involved in peripheral homing to the skin and entry into melanoma and other tumors, compared with T-cells sensitized by prostaglandin E2-matured DCs. ${ }^{11,112,114,116}$

\section{Helping vaccination-induced T-cells to work: conditioning tumor microenvironments for effective CTL entry and function}

Future developments in cancer immunotherapy research will likely focus on the challenges that vaccine-induced CTLs encounter in reaching the tumor microenvironment and performing their antitumor cytotoxic functions. Areas of current investigation in changing the tumor milieu include promoting CTL entry via chemokine modulation, inhibiting immune checkpoints that block CTL effector function, and decreasing immunosuppressive cells, such as regulatory T-cells and myeloid-derived suppressor cells.

Chemokine modulation aims to shift the balance of the tumor environment toward expression of effector T-cell attracting chemokines, and away from regulatory T-cell attracting chemokines. ${ }^{32}$ Tumor infiltration of certain immune cells such as CTLs, type 1 helper CD4+ T-cells, DCs, and M1 macrophages has positive prognostic value, while infiltration by regulatory T-cells, type 2 helper $\mathrm{CD} 4^{+} \mathrm{T}$-cells, myeloid-derived suppressor cells, and M2 macrophages is associated with poor outcomes. ${ }^{117-120}$ There are currently several monoclonal antibodies and small molecule inhibitors targeting various chemokine receptors in clinical trials. ${ }^{121}$ Our group has also shown that ex vivo treatment of tumor tissue with type 1 IFNs, a TLR-3 ligand, and a cyclo-oxygenase-2 inhibitor increased the production of the effector T-cell attracting chemokines, CCL5 and CXCL10, while decreasing the production of regulatory T-cells attracting chemokine CCL22. ${ }^{32}$

Combining vaccines with agents that reduce the levels of immunosuppressive cells (such as myeloid-derived suppressor cells and regulatory T-cells) has also been an attractive strategy. Low-dose cyclophosphamide has been used extensively for its ability to suppress regulatory T-cells since it is inexpensive and easily obtained. ${ }^{122} \mathrm{~A}$ randomized Phase II study of the renal cell cancer peptide vaccine, IMA901, demonstrated that a single cyclophosphamide dose was effective in reducing the number of regulatory T-cells, and that among patients who were immune responders, those treated with cyclophosphamide had increased survival. ${ }^{56}$ Another Phase I/II trial of a multipeptide-loaded DC vaccine in advanced ovarian cancer showed a trend toward increased survival with the addition of cyclophosphamide treatment. ${ }^{123}$ Other combination strategies to reduce regulatory T-cells in vaccine trials have included anti-CD25 monoclonal antibodies and a CD25 targeting immunotoxin. ${ }^{124,125}$ Preliminary data from an ongoing randomized DC vaccine trial targeting myeloidderived suppressor cells using all-trans-retinoic acid show that the treatment arm receiving all-trans-retinoic acid and vaccination had an improved immune response compared with vaccination alone. ${ }^{126}$ Other inhibitors of immunosuppressive targets shown to correlate with decreased survival, such as prostaglandin E2, indoleamine 2,3-dioxygenase, and nitric oxide synthase, are also potential targets for combinatorial therapy with cancer vaccines. ${ }^{127-130}$

In contrast with combinatorial therapies that reverse immunosuppressive cells, cancer vaccines may be combined with cytokine treatments that promote effector T-cell activity and prolong T-cell memory (see Figure 1C). IL-7, IL-15, IL-21, and IL-27 are similar to IL-2 as part of the common gamma chain cytokine receptor family. ${ }^{131}$ IL-7 has a role in development, homeostasis, and survival of T-cells and B-cells. ${ }^{132,133}$ Administration of recombinant IL-7 to cancer patients has been shown to be safe and to rapidly expand circulating CD4 and CD8 cells that express CD127, but not regulatory T-cells. ${ }^{134} \mathrm{IL}-15$ has a role in T-cell and natural killer cell activation and proliferation and maintenance of memory T-cell responses. ${ }^{135,136}$ Early phase clinical trials utilizing IL-15 for cancer treatment are ongoing or recently completed, but without published results as yet. ${ }^{136} \mathrm{IL}-21$ is produced by activated $\mathrm{CD} 4^{+} \mathrm{T}$-cells and natural killer T-cells, and contributes to antitumor immunity by its induction and activation of $\mathrm{CD}^{+} \mathrm{T}$-cells, natural killer cells, and natural 
killer T-cells. ${ }^{131,137,138}$ Early Phase I and II studies have shown encouraging results in metastatic melanoma and metastatic renal cell carcinoma. ${ }^{139-142}$ IL-27 is produced by antigen-presenting cells and can enhance $\mathrm{CD}^{+} \mathrm{T}$-cell and natural killer cell activation, but development of IL-27 as a therapeutic is still in preclinical stages. ${ }^{143,144}$

The approval by the US Food and Drug Administration of ipilimumab for metastatic melanoma in 2010 signaled a change in the landscape of cancer therapies. Ipilimumab (MDX-010, Yervoy ${ }^{\circledR}$; Bristol-Myers Squibb, New York, NY, USA) is a fully human monoclonal antibody against CTLA-4, and a homologue of CD28 with greater affinity to B7 molecules which outcompetes CD28 binding, effectually preventing the costimulatory signal $2 .{ }^{11}$ Anti-CTLA-4 antibodies block this inhibitory interaction or immune checkpoint and restore signal 2 for T-cell activation. In a randomized, double-blind, three-arm Phase III trial comparing ipilimumab with and without a glycoprotein 100 vaccine (MDX-1379) with vaccination alone in patients with metastatic melanoma, subjects in the ipilimumab treatment groups were found to have a significantly higher median survival compared with those receiving vaccination alone (10 months versus 6.4 months). ${ }^{46}$ The failure of the vaccination arms in the Phase III study to improve overall survival was unexpected, but it is possible that this resulted from the application of a single-epitope glycoprotein 100 peptide vaccine. A similar glycoprotein 100 vaccine did not show an improvement in survival, although that study was only powered to detect a difference in progression-free survival and not overall survival. ${ }^{47}$ Furthermore, the original Phase III study had ipilimumab and vaccination administration occurring concurrently, whereas there is more recent evidence from a murine model that sequential therapy of vaccination followed by anti-CTLA-4 antibody was superior to the anti-CTLA-4 antibody when administered first. ${ }^{145}$ Some of the early preclinical studies of ipilimumab indeed focused on using it in combination with cell-based cancer vaccines, and other anti-CTLA-4/vaccine combinations are in clinical trials. ${ }^{11,146-148}$ A recent Phase II study comparing ipilimumab alone or in combination with GM-CSF-secreting whole cell vaccine showed a higher survival rate when ipilimumab was combined with vaccine. ${ }^{146}$

Another actively studied immune checkpoint receptor is PD-1 (CD279). ${ }^{149}$ PD-1 and its ligands, PD-1 ligand 1 and 2 (PDL1 and PDL2), are expressed on more cell types than CTLA-4. PD-1 expression can be induced not only on activated T-cells, but also on B-cells and natural killer cells, while PDL1 and PDL 2 can be upregulated on tumor cells, antigenpresenting cells, and other cells in inflammatory conditions.
Several clinical trials of anti-PD-1 and anti-PDL1 antibodies have shown durable response rates. ${ }^{6,150-152}$ While studies using combinatorial PD pathway agents and vaccine therapy are not as advanced as those with anti-CTLA-4 agents, there is promising preclinical and early clinical trial data suggesting that the dual combination or even the triple combination with anti-CTLA-4/PD pathway blockade/vaccination therapy will have increased clinical benefit by further enhancing the antigen-specific T-cell response from vaccination and decreasing regulatory T-cells. ${ }^{153-157}$

An effective combinatorial vaccine therapy will likely need to address three goals: building a robust antigenspecific CTL response; altering the tumor microenvironment to allow CTL infiltration and reduce migration of regulatory T-cells and myeloid-derived suppressor cells; and counteracting CTL inhibitory mechanisms such as immune checkpoints that lead to immunosuppression (Figure 1). An encouraging study using a combination of a peptide vaccine, anti-PD-1 antibody, and low-dose cyclophosphamide in a murine tumor model demonstrated that this combination of drugs synergized in increasing survival and reducing tumor burden. ${ }^{158}$ One of the concerns about optimal application of complex immunotherapies is determination of the optimal sequence and duration of application of each of the components. It also needs to be determined how to optimally incorporate immunotherapy, different forms of which can either suppress or enhance both the induction of immune responses and the susceptibility of cancer tissues to immune attack.

\section{Conclusion}

Several of the new cancer vaccines have recently shown promise in prolonging patient survival. The next era of vaccine development is likely to involve both continued improvement of the vaccines themselves as well as combinatorial application of vaccines with agents that target the tumor microenvironment to promote entry of vaccination-induced cells, while eliminating local predominance of suppressive cells, and amplifying and prolonging the duration of the effector phase of antitumor immunity at tumor sites. The development of optimized immunotherapies for advanced cancer will also benefit from identification of the most relevant laboratory correlates of clinical effectiveness and integration of immunotherapy with other elements of comprehensive cancer care.

\section{Acknowledgment}

This work was supported by grants from the National Institutes of Health (CA113263, CA132714, CA159981). 


\section{Disclosure}

Alpha-type 1 polarized DCs, one of the types of DC discussed in this paper, are a topic of a recently issued US patent. None of the authors receives any form of support or remuneration related to that intellectual property. The authors report no other conflicts of interest in this work.

\section{References}

1. Siegel R, Naishadham D, Jemal A. Cancer statistics, 2013. CA Cancer Clin. 2013;63(1):11-30.

2. Nauts HC, Swift WE, Coley BL. The treatment of malignant tumors by bacterial toxins as developed by the late Coley WB, reviewed in the light of modern research. Cancer Res. 1946;6(4):205-216.

3. Palucka K, Banchereau J. Cancer immunotherapy via dendritic cells. Nat Rev Cancer. 2012;12(4):265-277.

4. Chen DS, Mellman I. Oncology meets immunology: the cancerimmunity cycle. Immunity. 2013;39(1):1-10.

5. Blattman JN, Greenberg PD. Cancer immunotherapy: a treatment for the masses. Science. 2004;305(5681):200-205.

6. Hamid O, Robert C, Daud A, et al. Safety and tumor responses with lambrolizumab (anti-PD-1) in melanoma. $N$ Engl J Med. 2013;369(2):134-144.

7. Wolchok JD, Kluger H, Callahan MK, et al. Nivolumab plus ipilimumab in advanced melanoma. $N$ Engl J Med. 2013;369(2):122-133.

8. Vacchelli E, Galluzzi L, Eggermont A, et al. Trial watch: FDA-approved Toll-like receptor agonists for cancer therapy. Oncoimmunology. 2012;1(6):894-907.

9. Eggermont AM, Suciu S, Testori A, et al. Long-term results of the randomized phase III Trial EORTC 18991 of adjuvant therapy with pegylated interferon alfa-2b versus observation in resected stage III melanoma. J Clin Oncol. 2012;30(31):3810-3818.

10. Clement JM, McDermott DF. The high-dose aldesleukin (IL-2) "SELECT" trial: a trial designed to prospectively validate predictive models of response to high-dose IL-2 treatment in patients with metastatic renal cell carcinoma. Clin Genitourin Cancer. 2009;7(2):E7-E9.

11. Lipson EJ, Drake CG. Ipilimumab: an anti-CTLA-4 antibody for metastatic melanoma. Clin Cancer Res. 2011;17(22):6958-6962.

12. Goldman B, DeFrancesco L. The cancer vaccine roller coaster. Nat Biotechnol. 2009;27(2):129-139.

13. Rice J, Ottensmeier CH, Stevenson FK. DNA vaccines: precision tools for activating effective immunity against cancer. Nat Rev Cancer. 2008;8(2):108-120.

14. Larocca C, Schlom J. Viral vector-based therapeutic cancer vaccines. Cancer J. 2011;17(5):359-371.

15. Bartlett DL, Liu Z, Sathaiah M, et al. Oncolytic viruses as therapeutic cancer vaccines. Mol Cancer. 2013;12(1):103.

16. Mockey M, Bourseau E, Chandrashekhar V, et al. mRNA-based cancer vaccine: prevention of B16 melanoma progression and metastasis by systemic injection of MART1 mRNA histidylated lipopolyplexes. Cancer Gene Ther. 2007;14(9):802-814.

17. Diken M, Kreiter S, Selmi A, Tureci O, Sahin U. Antitumor vaccination with synthetic mRNA: strategies for in vitro and in vivo preclinical studies. Methods Mol Biol. 2013;969:235-246.

18. Fotin-Mleczek M, Duchardt KM, Lorenz C, et al. Messenger RNA-based vaccines with dual activity induce balanced TLR-7 dependent adaptive immune responses and provide antitumor activity. $J$ Immunother. 2011;34(1):1-15.

19. Heimburg-Molinaro J, Lum M, Vijay G, Jain M, Almogren A, Rittenhouse-Olson K. Cancer vaccines and carbohydrate epitopes. Vaccine. 2011;29(48):8802-8826.

20. Almand B, Resser JR, Lindman B, et al. Clinical significance of defective dendritic cell differentiation in cancer. Clin Cancer J. 2000;6(5):1755-1766.
21. Della Bella S, Gennaro M, Vaccari M, et al. Altered maturation of peripheral blood dendritic cells in patients with breast cancer. $\mathrm{Br} J$ Cancer. 2003;89(8):1463-1472.

22. Obermajer N, Muthuswamy R, Lesnock J, Edwards RP, Kalinski P. Positive feedback between PGE2 and COX2 redirects the differentiation of human dendritic cells toward stable myeloid-derived suppressor cells. Blood. 2011;118(20):5498-5505.

23. Obermajer N, Kalinski P. Key role of the positive feedback between PGE(2) and COX2 in the biology of myeloid-derived suppressor cells. Oncoimmunology. 2012;1(5):762-764.

24. Nakamura Y, Watchmaker P, Urban J, et al. Helper function of memory CD8+ T cells: heterologous CD8+T cells support the induction of therapeutic cancer immunity. Cancer Res. 2007;67(20):10012-10018.

25. Watchmaker PB, Urban JA, Berk E, et al. Memory CD8+ T cells protect dendritic cells from CTL killing. J Immunol. 2008;180(6): 3857-3865.

26. Cooper AM, Khader SA. The role of cytokines in the initiation, expansion, and control of cellular immunity to tuberculosis. Immunol Rev. 2008;226:191-204.

27. Haring JS, Badovinac VP, Harty JT. Inflaming the CD8+T cell response. Immunity. 2006;25(1):19-29.

28. Kalinski P, Okada H. Polarized dendritic cells as cancer vaccines: directing effector-type T cells to tumors. Semin Immunol. 2010;22(3): 173-182.

29. Hartl D, Krauss-Etschmann S, Koller B, et al. Infiltrated neutrophils acquire novel chemokine receptor expression and chemokine responsiveness in chronic inflammatory lung diseases. J Immunol. 2008;181(11):8053-8067.

30. Zou W. Regulatory T cells, tumour immunity and immunotherapy. Nat Rev Immunol. 2006;6(4):295-307.

31. Curiel TJ, Coukos G, Zou L, et al. Specific recruitment of regulatory $\mathrm{T}$ cells in ovarian carcinoma fosters immune privilege and predicts reduced survival. Nat Med. 2004;10(9):942-949.

32. Muthuswamy R, Berk E, Junecko BF, et al. NF-kappaB hyperactivation in tumor tissues allows tumor-selective reprogramming of the chemokine microenvironment to enhance the recruitment of cytolytic T effector cells. Cancer Res. 2012;72(15): 3735-3743.

33. Zou W, Machelon V, Coulomb-L'Hermin A, et al. Stromal-derived factor- 1 in human tumors recruits and alters the function of plasmacytoid precursor dendritic cells. Nat Med. 2001;7(12):1339-1346.

34. Obermajer N, Muthuswamy R, Odunsi K, Edwards RP, Kalinski P. PGE(2)-induced CXCL12 production and CXCR4 expression controls the accumulation of human MDSCs in ovarian cancer environment. Cancer Res. 2011;71(24):7463-7470.

35. Kryczek I, Wei S, Keller E, Liu R, Zou W. Stroma-derived factor (SDF-1/CXCL12) and human tumor pathogenesis. Am J Physiol Cell Physiol. 2007;292(3):C987-C995.

36. Melief CJ. Cancer immunotherapy by dendritic cells. Immunity. 2008;29(3):372-383.

37. Rabinovich GA, Gabrilovich D, Sotomayor EM. Immunosuppressive strategies that are mediated by tumor cells. Annu Rev Immunol. 2007;25:267-296.

38. Uchida K, Schneider S, Yochim JM, et al. Intratumoral COX-2 gene expression is a predictive factor for colorectal cancer response to fluoropyrimidine-based chemotherapy. Clin Cancer Res. 2005;11(9): 3363-3368.

39. Banerjee DK, Dhodapkar MV, Matayeva E, Steinman RM, Dhodapkar KM. Expansion of FOXP3 high regulatory T cells by human dendritic cells (DCs) in vitro and after injection of cytokine-matured DCs in myeloma patients. Blood. 2006;108(8):2655-2661.

40. Vieweg J, Su Z, Dahm P, Kusmartsev S. Reversal of tumor-mediated immunosuppression. Clin Cancer Res. 2007;13(2 Pt 2):727s-732s.

41. Sheikh NA, Petrylak D, Kantoff PW, et al. Sipuleucel-T immune parameters correlate with survival: an analysis of the randomized phase 3 clinical trials in men with castration-resistant prostate cancer. Cancer Immunol Immunother. 2013;62(1):137-147. 
42. Cheever MA, Higano CS. Provenge (Sipuleucel-T) in prostate cancer: the first FDA-approved therapeutic cancer vaccine. Clin Cancer Res. 2011;17(11):3520-3526.

43. Kantoff PW, Higano CS, Shore ND, et al. Sipuleucel-T immunotherapy for castration-resistant prostate cancer. $N$ Engl J Med. 2010;363(5): 411-422.

44. Higano CS, Schellhammer PF, Small EJ, et al. Integrated data from 2 randomized, double-blind, placebo-controlled, phase 3 trials of active cellular immunotherapy with sipuleucel-T in advanced prostate cancer Cancer. 2009;115(16):3670-3679.

45. ClinicalTrials.gov. National Institutes of Health, Bethesda, MD, USA: Available from: http://www.ClinicalTrials.gov. Accessed November 28, 2013.

46. Hodi FS, O'Day SJ, McDermott DF, et al. Improved survival with ipilimumab in patients with metastatic melanoma. $N$ Engl $J$ Med. 2010;363(8):711-723.

47. Schwartzentruber DJ, Lawson DH, Richards JM, et al. gp100 peptide vaccine and interleukin-2 in patients with advanced melanoma. $N$ Engl JMed. 2011;364(22):2119-2127.

48. Middleton GW, Valle JW, Wadsley J, et al. A phase III randomized trial of chemoimmunotherapy comprising gemcitabine and capecitabine with or without telomerase vaccine GV1001 in patients with locally advanced or metastatic pancreatic cancer. J Clin Oncol. 2013; 31(Suppl 15):Abstr LBA4004

49. Quoix E, Ramlau R, Westeel V, et al. Therapeutic vaccination with TG4010 and first-line chemotherapy in advanced nonsmall-cell lung cancer: a controlled phase 2B trial. Lancet Oncol. 2011;12(12):1125-1133.

50. Hardacre JM, Mulcahy M, Small W, et al. Addition of algenpantucel-L immunotherapy to standard adjuvant therapy for pancreatic cancer: a phase 2 study. J Gastrointest Surg. 2013;17(1):94-100.

51. Morris JC, Rossi GR, Harold N, et al. Potential chemo-sensitization effect of tergenpumatucel-L immunotherapy in treated patients with advanced non-small cell lung cancer (NSCLC). J Clin Oncol. 2013;31(Supp1 15):Abstr 8094.

52. Bandman O, Delcayre A, Laus R, et al. PROSPECT: A randomized, double-blind, phase III efficacy trial of PROSTVAC. J Clin Oncol. 2012;30(Suppl 15):Abstr TPS4699.

53. Giaccone G, Bazhenova L, Nemunaitis J, et al. A phase III study of belagenpumatucel-L therapeutic tumor cell vaccine for non-small cell lung cancer (NSCLC). Available from: http://eccamsterdam2013.eccoorg.eu/Scientific-Programme/Abstract-search.aspx?abstractid=8961. Accessed November 28, 2013

54. Butts C, Socinski MA, Mitchell PL, et al. Tecemotide (L-BLP25) versus placebo after chemoradiotherapy for stage III non-small-cell lung cancer (START): a randomised, double-blind, phase 3 trial. Lancet Oncol. 2014;15(1):59-68.

55. Lawson DH, Lee SJ, Tarhini AA, Margolin KA, Ernstoff MS, Kirkwood JM. E4697: Phase III cooperative group study of yeastderived granulocyte macrophage colony-stimulating factor (GM-CSF) versus placebo as adjuvant treatment of patients with completely resected stage III-IV melanoma. J Clin Oncol. 2010;28(Suppl 15): Abstr 8504.

56. Walter S, Weinschenk T, Stenzl A, et al. Multipeptide immune response to cancer vaccine IMA901 after single-dose cyclophosphamide associates with longer patient survival. Nat Med. 2012;18(8): 1254-1261.

57. Therasse P, Vansteenkiste JF, Zielinski M, et al. MAGRIT phase III trial: MAGE-A3 antigen-specific cancer immunotherapy (ASCI) as adjuvant therapy in patients with completely resected stage IB-IIIA NSCLC. J Clin Oncol. 2011;29(Suppl 15):Abstr TPS210.

58. GlaxoSmithKline. The investigational MAGE-A3 antigen-specific cancer immunotherapeutic does not meet first co-primary endpoint in Phase III melanoma clinical trial, 2013. Available from: http:// www.gsk.com/media/press-releases/2013/the-investigational-magea3-antigen-specific-cancer-immunotherap.html. Accessed January 14, 2014.
59. GlaxoSmithKline. Update on phase III clinical trial of investigational MAGE-A3 antigen-specific cancer immunotherapeutic in non-small cell lung cancer, 2014. Available from: http://www. gsk.com/media/press-releases/2014/update-on-phase-III-clinicaltrial-of-investigational-MAGE-A3-antigen-specific-cancer-immunotherapeutic-in-non-small-cell-lung-cancer.html. Accessed June 19, 2014.

60. Ulloa-Montoya F, Louahed J, Dizier B, et al. Predictive gene signature in MAGE-A3 antigen-specific cancer immunotherapy. J Clin Oncol. 2013;31(19):2388-2395.

61. Vansteenkiste J, Zielinski M, Linder A, et al. Adjuvant MAGE-A3 immunotherapy in resected non-small-cell lung cancer: phase II randomized study results. J Clin Oncol. 2013;31(19):2396-2403.

62. Morton DL, Mozzillo N, Thompson JF, et al. An international, randomized, phase III trial of bacillus Calmette-Guerin (BCG) plus allogeneic melanoma vaccine $(\mathrm{MCV})$ or placebo after complete resection of melanoma metastatic to regional or distant sites. J Clin Oncol. 2007; 25(Suppl 18):Abstr 8508.

63. Hoshimoto S, Faries MB, Morton DL, et al. Assessment of prognostic circulating tumor cells in a phase III trial of adjuvant immunotherapy after complete resection of stage IV melanoma. Ann Surg. 2012;255(2): 357-362.

64. Eggermont AM, Suciu S, Rutkowski P, et al. Adjuvant ganglioside GM2-KLH/QS-21 vaccination versus observation after resection of primary tumor $>1.5 \mathrm{~mm}$ in patients with stage II melanoma: results of the EORTC 18961 randomized phase III trial. J Clin Oncol. 2013;31(30): 3831-3837.

65. Gulley JL, Madan RA, Schlom J. Impact of tumour volume on the potential efficacy of therapeutic vaccines. Curr Oncol. 2011;18(3): e150-e157.

66. Schlom J. Therapeutic cancer vaccines: current status and moving forward. J Natl Cancer Inst. 2012;104(8):599-613.

67. Wolchok JD, Hoos A, O’Day S, et al. Guidelines for the evaluation of immune therapy activity in solid tumors: immune-related response criteria. Clin Cancer Res. 2009;15(23):7412-7420.

68. Schlom J, Arlen PM, Gulley JL. Cancer vaccines: moving beyond current paradigms. Clin Cancer Res. 2007;13(13):3776-3782.

69. Bilusic M, Gulley JL. Endpoints, patient selection, and biomarkers in the design of clinical trials for cancer vaccines. Cancer Immunol Immunother. 2012;61(1):109-117.

70. Harrop R, Treasure P, de Belin J, et al. Analysis of pre-treatment markers predictive of treatment benefit for the therapeutic cancer vaccine MVA-5T4 (TroVax). Cancer Immunol Immunother. 2012;61(12): 2283-2294.

71. Skachkova OV, Khranovska NM, Gorbach OI, Svergun NM, Sydor RI, Nikulina VV. Immunological markers of anti-tumor dendritic cells vaccine efficiency in patients with non-small cell lung cancer. Exp Oncol. 2013;35(2):109-113.

72. Cornforth AN, Lee GJ, Fowler AW, Carbonell DJ, Dillman RO. Increases in serum TARC/CCL17 levels are associated with progressionfree survival in advanced melanoma patients in response to dendritic cell-based immunotherapy. J Clin Immunol. 2009;29(5):657-664.

73. Lopez MN, Pereda C, Segal G, et al. Prolonged survival of dendritic cellvaccinated melanoma patients correlates with tumor-specific delayed type IV hypersensitivity response and reduction of tumor growth factor beta-expressing T cells. J Clin Oncol. 2009;27(6):945-952.

74. Okada H, Kalinski P, Ueda R, et al. Induction of CD8+ T-cell responses against novel glioma-associated antigen peptides and clinical activity by vaccinations with \{alpha\}-type 1 polarized dendritic cells and polyinosinic-polycytidylic acid stabilized by lysine and carboxymethylcellulose in patients with recurrent malignant glioma. J Clin Oncol. 2011;29(3):330-336.

75. Carreno BM, Becker-Hapak M, Huang A, et al. IL-12p70-producing patient DC vaccine elicits Tc1-polarized immunity. J Clin Invest. 2013;123(8):3383-3394.

76. Palucka K, Ueno H, Banchereau J. Recent developments in cancer vaccines. J Immunol. 2011;186(3):1325-1331. 
77. Herber DL, Cao W, Nefedova Y, et al. Lipid accumulation and dendritic cell dysfunction in cancer. Nat Med. 2010;16(8):880-886.

78. Pinzon-Charry A, Maxwell T, Lopez JA. Dendritic cell dysfunction in cancer: a mechanism for immunosuppression. Immunol Cell Biol. 2005;83(5):451-461.

79. Dillman RO, Cornforth AN, Depriest C, et al. Tumor stem cell antigens as consolidative active specific immunotherapy: a randomized phase II trial of dendritic cells versus tumor cells in patients with metastatic melanoma. J Immunother. 2012;35(8):641-649.

80. Kalinski P. Dendritic cells in immunotherapy of established cancer: roles of signals 1, 2, 3 and 4. Curr Opin Investig Drugs. 2009;10(6): 526-535.

81. Banchereau J, Steinman RM. Dendritic cells and the control of immunity. Nature. 1998;392(6673):245-252.

82. Chiang CL, Kandalaft LE, Tanyi J, et al. A dendritic cell vaccine pulsed with autologous hypochlorous acid-oxidized ovarian cancer lysate primes effective broad antitumor immunity: from bench to bedside. Clin Cancer Res. 2013;19(17):4801-4815.

83. Reyes D, Salazar L, Espinoza E, et al. Tumour cell lysate-loaded dendritic cell vaccine induces biochemical and memory immune response in castration-resistant prostate cancer patients. Br J Cancer. 2013;109(6):1488-1497.

84. Strome SE, Voss S, Wilcox R, et al. Strategies for antigen loading of dendritic cells to enhance the antitumor immune response. Cancer Res. 2002;62(6):1884-1889.

85. Albert ML, Sauter B, Bhardwaj N. Dendritic cells acquire antigen from apoptotic cells and induce class I-restricted CTLs. Nature. 1998;392(6671):86-89.

86. Kalinski P, Muthuswamy R, Urban J. Dendritic cells in cancer immunotherapy: vaccines and combination immunotherapies. Exp Rev Vaccines. 2013;12(3):285-295.

87. Andersen BM, Ohlfest JR. Increasing the efficacy of tumor cell vaccines by enhancing cross priming. Cancer Lett. 2012;325(2):155-164.

88. Grakoui A, Bromley SK, Sumen C, et al. The immunological synapse: a molecular machine controlling $\mathrm{T}$ cell activation. Science. 1999;285(5425):221-227.

89. Hawiger D, Inaba K, Dorsett $Y$, et al. Dendritic cells induce peripheral $\mathrm{T}$ cell unresponsiveness under steady state conditions in vivo. $J$ Exp Med. 2001;194(6):769-779.

90. de Vries IJ, Lesterhuis WJ, Scharenborg NM, et al. Maturation of dendritic cells is a prerequisite for inducing immune responses in advanced melanoma patients. Clin Cancer Res. 2003;9(14): $5091-5100$

91. Adema GJ, de Vries IJ, Punt CJ, Figdor CG. Migration of dendritic cell based cancer vaccines: in vivo veritas? Curr Opin Immunol. 2005;17(2):170-174.

92. Reddy A, Sapp M, Feldman M, Subklewe M, Bhardwaj N. A monocyte conditioned medium is more effective than defined cytokines in mediating the terminal maturation of human dendritic cells. Blood. 1997;90(9):3640-3646.

93. Jonuleit H, Kuhn U, Muller G, et al. Pro-inflammatory cytokines and prostaglandins induce maturation of potent immunostimulatory dendritic cells under fetal calf serum-free conditions. Eur J Immunol. 1997;27(12):3135-3142.

94. Schadendorf D, Ugurel S, Schuler-Thurner B, et al. Dacarbazine (DTIC) versus vaccination with autologous peptide-pulsed dendritic cells (DC) in first-line treatment of patients with metastatic melanoma: a randomized phase III trial of the DC study group of the DeCOG. Ann Oncol. 2006;17(4):563-570.

95. Kalinski P, Hilkens CM, Wierenga EA, Kapsenberg ML. T-cell priming by type- 1 and type- 2 polarized dendritic cells: the concept of a third signal. Immunol Today. 1999;20(12):561-567.

96. Kalinski P. Regulation of immune responses by prostaglandin E2. J Immunol. 2012;188(1):21-28.

97. Watchmaker PB, Berk E, Muthuswamy R, et al. Independent regulation of chemokine responsiveness and cytolytic function versus CD8+ T cell expansion by dendritic cells. J Immunol. 2010;184(2): 591-597.
98. Mailliard RB, Son YI, Redlinger R, et al. Dendritic cells mediate NK cell help for Th1 and CTL responses: two-signal requirement for the induction of NK cell helper function. J Immunol. 2003;171(5):2366-2373.

99. Mailliard RB, Egawa S, Cai Q, et al. Complementary dendritic cellactivating function of CD8+ and CD4+ T cells: helper role of CD8+ $\mathrm{T}$ cells in the development of $\mathrm{T}$ helper type 1 responses. $J$ Exp Med. 2002;195(4):473-483.

100. Berk E, Kalinski P. Lymphocyte-polarized DC1s: Effective inducers of tumor-specific CTLs. Oncoimmunology. 2012;1(8): 1443-1444.

101. Berk E, Muthuswamy R, Kalinski P. Lymphocyte-polarized dendritic cells are highly effective in inducing tumor-specific CTLs. Vaccine. 2012;30(43):6216-6224.

102. Mailliard RB, Wankowicz-Kalinska A, Cai Q, et al. alpha-type-1 polarized dendritic cells: a novel immunization tool with optimized CTL-inducing activity. Cancer Res. 2004;64(17):5934-5937.

103. Vieira PL, de Jong EC, Wierenga EA, Kapsenberg ML, Kalinski P. Development of Th1-inducing capacity in myeloid dendritic cells requires environmental instruction. J Immunol. 2000;164(9): $4507-4512$.

104. Wesa A, Kalinski P, Kirkwood JM, Tatsumi T, Storkus WJ. Polarized type-1 dendritic cells (DC1) producing high levels of IL-12 family members rescue patient TH1-type antimelanoma CD4+ T cell responses in vitro. J Immunother. 2007;30(1):75-82.

105. Roses RE, Xu S, Xu M, Koldovsky U, Koski G, Czerniecki BJ. Differential production of IL-23 and IL-12 by myeloid-derived dendritic cells in response to TLR agonists. J Immunol. 2008;181(7): 5120-5127.

106. Paustian C, Caspell R, Johnson T, et al. Effect of multiple activation stimuli on the generation of Th1-polarizing dendritic cells. Hum Immunol. 2011;72(1):24-31.

107. Ten Brinke A, Karsten ML, Dieker MC, Zwaginga JJ, van Ham SM. The clinical grade maturation cocktail monophosphoryl lipid A plus IFNgamma generates monocyte-derived dendritic cells with the capacity to migrate and induce Th1 polarization. Vaccine. 2007;25(41):7145-7152.

108. Lopez-Albaitero A, Mailliard R, Hackman T, et al. Maturation pathways of dendritic cells determine TAP1 and TAP2 levels and crosspresenting function. $J$ Immunother. 2009;32(5):465-473.

109. Wieckowski E, Chatta GS, Mailliard RM, et al. Type-1 polarized dendritic cells loaded with apoptotic prostate cancer cells are potent inducers of CD8(+) T cells against prostate cancer cells and defined prostate cancer-specific epitopes. Prostate. 2011;71(2): 125-133.

110. Lee JJ, Foon KA, Mailliard RB, Muthuswamy R, Kalinski P. Type 1polarized dendritic cells loaded with autologous tumor are a potent immunogen against chronic lymphocytic leukemia. J Leukoc Biol. 2008;84(1):319-325.

111. Muthuswamy R, Mueller-Berghaus J, Haberkorn U, Reinhart TA, Schadendorf D, Kalinski P. PGE(2) transiently enhances DC expression of CCR7 but inhibits the ability of DCs to produce CCL19 and attract naive T cells. Blood. 2010;116(9):1454-1459.

112. Muthuswamy R, Urban J, Lee JJ, Reinhart TA, Bartlett D, Kalinski P. Ability of mature dendritic cells to interact with regulatory $\mathrm{T}$ cells is imprinted during maturation. Cancer Res. 2008;68(14):5972-5978.

113. Gustafsson K, Ingelsten M, Bergqvist L, Nystrom J, Andersson B, Karlsson-Parra A. Recruitment and activation of natural killer cells in vitro by a human dendritic cell vaccine. Cancer Res. 2008;68(14): 5965-5971.

114. Kunz M, Toksoy A, Goebeler M, Engelhardt E, Brocker E, Gillitzer R. Strong expression of the lymphoattractant C-X-C chemokine Mig is associated with heavy infiltration of $\mathrm{T}$ cells in human malignant melanoma. J Pathol. 1999;189(4):552-558.

115. Calzascia T, Masson F, Di Berardino-Besson W, et al. Homing phenotypes of tumor-specific CD8 $\mathrm{T}$ cells are predetermined at the tumor site by crosspresenting APCs. Immunity. 2005;22(2):175-184. 
116. Wenzel J, Bekisch B, Uerlich M, Haller O, Bieber T, Tuting T. Type I interferon-associated recruitment of cytotoxic lymphocytes: a common mechanism in regressive melanocytic lesions. Am J Clin Pathol. 2005;124(1):37-48.

117. Salama P, Phillips M, Grieu F, et al. Tumor-infiltrating FOXP3+ $\mathrm{T}$ regulatory cells show strong prognostic significance in colorectal cancer. J Clin Oncol. 2009;27(2):186-192.

118. Senovilla L, Vacchelli E, Galon J, et al. Trial watch: prognostic and predictive value of the immune infiltrate in cancer. Oncoimmunology. 2012;1(8):1323-1343.

119. Fridman WH, Pages F, Sautes-Fridman C, Galon J. The immune contexture in human tumours: impact on clinical outcome. Nat Rev Cancer. 2012;12(4):298-306.

120. Galon J, Costes A, Sanchez-Cabo F, et al. Type, density, and location of immune cells within human colorectal tumors predict clinical outcome. Science. 2006;313(5795):1960-1964.

121. Lazennec G, Richmond A. Chemokines and chemokine receptors: new insights into cancer-related inflammation. Trends Mol Med. 2010;16(3):133-144.

122. Le DT, Jaffee EM. Regulatory T-cell modulation using cyclophosphamide in vaccine approaches: a current perspective. Cancer Res. 2012;72(14):3439-3444.

123. Chu CS, Boyer J, Schullery DS, et al. Phase I/II randomized trial of dendritic cell vaccination with or without cyclophosphamide for consolidation therapy of advanced ovarian cancer in first or second remission. Cancer Immunol Immunother. 2012;61(5):629-641.

124. Morse MA, Hobeika AC, Osada T, et al. Depletion of human regulatory $\mathrm{T}$ cells specifically enhances antigen-specific immune responses to cancer vaccines. Blood. 2008;112(3):610-618.

125. Jacobs JF, Punt CJ, Lesterhuis WJ, et al. Dendritic cell vaccination in combination with anti-CD25 monoclonal antibody treatment: a phase I/II study in metastatic melanoma patients. Clin Cancer Res. 2010;16(20):5067-5078.

126. Iclozan C, Antonia S, Chiappori A, Chen DT, Gabrilovich D. Therapeutic regulation of myeloid-derived suppressor cells and immune response to cancer vaccine in patients with extensive stage small cell lung cancer. Cancer Immunol Immunther. 2013;62(5): 909-918.

127. Ou X, Cai S, Liu P, et al. Enhancement of dendritic cell-tumor fusion vaccine potency by indoleamine-pyrrole 2,3-dioxygenase inhibitor, 1-MT. J Cancer Res Clin Oncol. 2008;134(5):525-533.

128. Basu GD, Tinder TL, Bradley JM, et al. Cyclooxygenase-2 inhibitor enhances the efficacy of a breast cancer vaccine: role of IDO. J Immunol. 2006;177(4):2391-2402.

129. Zhang H, Tian M, Xiu C, Wang Y, Tang G. Enhancement of antitumor activity by combination of tumor lysate-pulsed dendritic cells and celecoxib in a rat glioma model. Oncol Res. 2013;20(10): 447-455.

130. Takaoka K, Hidaka S, Hashitani S, et al. Effect of a nitric oxide synthase inhibitor and a CXC chemokine receptor- 4 antagonist on tumor growth and metastasis in a xenotransplanted mouse model of adenoid cystic carcinoma of the oral floor. Int J Oncol. 2013;43(3): 737-745.

131. Santegoets SJ, Turksma AW, Powell DJ Jr, Hooijberg E, de Gruijl TD. IL-21 in cancer immunotherapy: at the right place at the right time. Oncoimmunology. 2013;2(6):e24522.

132. Perna SK, Pagliara D, Mahendravada A, et al. Interleukin-7 mediates selective expansion of tumor-redirected cytotoxic T lymphocytes (CTLs) without enhancement of regulatory T-cell inhibition. Clin Cancer Res. 2014;20(1):131-139.

133. Mackall CL, Fry TJ, Gress RE. Harnessing the biology of IL-7 for therapeutic application. Nat Rev. 2011;11(5):330-342.

134. Rosenberg SA, Sportes C, Ahmadzadeh M, et al. IL-7 administration to humans leads to expansion of $\mathrm{CD} 8+$ and $\mathrm{CD} 4+$ cells but a relative decrease of CD4+ T-regulatory cells. J Immunother. 2006;29(3): 313-319.

135. Waldmann TA. The biology of interleukin-2 and interleukin-15: implications for cancer therapy and vaccine design. Nat Rev Immunol. 2006;6(8):595-601.
136. Steel JC, Waldmann TA, Morris JC. Interleukin- 15 biology and its therapeutic implications in cancer. Trends Pharm Sci. 2012;33(1):35-41.

137. Skak K, Kragh M, Hausman D, Smyth MJ, Sivakumar PV. Interleukin 21: combination strategies for cancer therapy. Nat Rev Drug Discov. 2008;7(3):231-240.

138. Frederiksen KS, Lundsgaard D, Freeman JA, et al. IL-21 induces in vivo immune activation of $\mathrm{NK}$ cells and $\mathrm{CD} 8(+) \mathrm{T}$ cells in patients with metastatic melanoma and renal cell carcinoma. Cancer Immunol Immunother. 2008;57(10):1439-1449.

139. Petrella TM, Tozer R, Belanger K, et al. Interleukin- 21 has activity in patients with metastatic melanoma: a phase II study. J Clin Oncol. 2012;30(27):3396-3401.

140. Thompson JA, Curti BD, Redman BG, et al. Phase I study of recombinant interleukin-21 in patients with metastatic melanoma and renal cell carcinoma. J Clin Oncol. 2008;26(12):2034-2039.

141. Schmidt H, Brown J, Mouritzen U, et al. Safety and clinical effect of subcutaneous human interleukin-21 in patients with metastatic melanoma or renal cell carcinoma: a phase I trial. Clin Cancer Res. 2010;16(21):5312-5319.

142. Hashmi MH, Van Veldhuizen PJ. Interleukin-21: updated review of Phase I and II clinical trials in metastatic renal cell carcinoma, metastatic melanoma and relapsed/refractory indolent non-Hodgkin's lymphoma. Expert Opin Biol Ther. 2010;10(5):807-817.

143. Murugaiyan G, Saha B. IL-27 in tumor immunity and immunotherapy. Trends Mol Med. 2013;19(2):108-116.

144. Swarbrick A, Junankar SR, Batten M. Could the properties of IL-27 make it an ideal adjuvant for anticancer immunotherapy? Oncoimmunology. 2013;2(8):e25409.

145. Wada S, Jackson CM, Yoshimura K, et al. Sequencing CTLA-4 blockade with cell-based immunotherapy for prostate cancer. J Transl Med. 2013;11:89.

146. Le DT, Lutz E, Uram JN, et al. Evaluation of ipilimumab in combination with allogeneic pancreatic tumor cells transfected with a GM-CSF gene in previously treated pancreatic cancer. $J$ Immunother. 2013;36(7):382-389.

147. Madan RA, Mohebtash M, Arlen PM, et al. Ipilimumab and a poxviral vaccine targeting prostate-specific antigen in metastatic castration-resistant prostate cancer: a phase 1 dose-escalation trial. Lancet Oncol. 2012;13(5):501-508.

148. Ribas A, Comin-Anduix B, Chmielowski B, et al. Dendritic cell vaccination combined with CTLA4 blockade in patients with metastatic melanoma. Clin Cancer Res. 2009;15(19):6267-6276.

149. Pardoll DM. The blockade of immune checkpoints in cancer immunotherapy. Nat Rev Cancer. 2012;12(4):252-264.

150. Brahmer JR, Drake CG, Wollner I, et al. Phase I study of singleagent anti-programmed death-1 (MDX-1106) in refractory solid tumors: safety, clinical activity, pharmacodynamics, and immunologic correlates. J Clin Oncol. 2010;28(19):3167-3175.

151. Brahmer JR, Tykodi SS, Chow LQ, et al. Safety and activity of anti-PD-L1 antibody in patients with advanced cancer. $N$ Engl $J$ Med. 2012;366(26):2455-2465.

152. Lipson EJ, Sharfman WH, Drake CG, et al. Durable cancer regression off-treatment and effective reinduction therapy with an anti-PD-1 antibody. Clin Cancer Res. 2013;19(2):462-468.

153. Sierro SR, Donda A, Perret R, et al. Combination of lentivector immunization and low-dose chemotherapy or PD-1/PD-L1 blocking primes self-reactive $\mathrm{T}$ cells and induces anti-tumor immunity. Eur $J$ Immunol. 2011;41(8):2217-2228.

154. Rosenblatt J, Glotzbecker B, Mills H, et al. PD-1 blockade by CT-011, anti-PD-1 antibody, enhances ex vivo T-cell responses to autologous dendritic cell/myeloma fusion vaccine. $J$ Immunother. 2011;34(5): 409-418.

155. Li B, VanRoey M, Wang C, Chen TH, Korman A, Jooss K. Anti-programmed death-1 synergizes with granulocyte macrophage colony-stimulating factor- secreting tumor cell immunotherapy providing therapeutic benefit to mice with established tumors. Clin Cancer Res. 2009;15(5):1623-1634. 
156. Duraiswamy J, Kaluza KM, Freeman GJ, Coukos G. Dual blockade of PD-1 and CTLA-4 combined with tumor vaccine effectively restores T-cell rejection function in tumors. Cancer Res. 2013;73(12):3591-3603.

157. Weber JS, Kudchadkar RR, Gibney GT, et al. Phase I/II trial of PD-1 antibody nivolumab with peptide vaccine in patients naive to or that failed ipilimumab. J Clin Oncol. 2013;31(Suppl 15):Abstr 9011.
158. Mkrtichyan M, NajjarYG, Raulfs EC, et al. Anti-PD-1 synergizes with cyclophosphamide to induce potent anti-tumor vaccine effects through novel mechanisms. Eur J Immunol. 2011;41(10):2977-2986.

\section{Publish your work in this journal}

ImmunoTargets and Therapy is an international, peer-reviewed open access journal focusing on the immunological basis of diseases, potential targets for immune based therapy and treatment protocols employed to improve patient management. Basic immunology and physiology of the immune system in health, and disease will be also covered. In addition, the journal will focus on the impact of manage-

\section{Dovepress}

ment programs and new therapeutic agents and protocols on patient perspectives such as quality of life, adherence and satisfaction. The manuscript management system is completely online and includes a very quick and fair peer-review system, which is all easy to use. Visit http://www.dovepress.com/testimonials.php to read real quotes from published authors.

Submit your manuscript here: http://www.dovepress.com/immunotargets-and-therapy-journal 